\title{
Spatial Differentiation of Border Areas of the Central Black Earth Region in Metropolisation Processes
}

\author{
Nadezhda Chugunova \\ Belgorod State National Research University \\ Belgorod, Russia \\ Chugunova@bsu.edu.ru \\ Tatyana Polyakova \\ Belgorod State National Research University \\ Belgorod, Russia \\ Chugunova@bsu.edu.ru \\ D. Morkovskaya \\ Belgorod State National Research University \\ Belgorod, Russia \\ Chugunova@bsu.edu.ru
}

\author{
Anastasiya Narozhnaya \\ Belgorod State National Research University \\ Belgorod, Russia \\ Chugunova@bsu.edu.ru \\ Nataliya Kuharuk \\ Belgorod State National Research University \\ Belgorod, Russia \\ Chugunova@bsu.edu.ru
}

\begin{abstract}
Spatial socio-economic and ekistical differentiation of the Russian regions will never lose its relevance due to their vast territories, significant differences in settlement systems, and socioeconomic activities of their entities. The differences are clearly manifested in the border areas. A feature of the Belgorod, Voronezh, Kursk regions is their border position with the Ukraine, which has left noticeable imprints on the population of border areas and a number of socio-economic indicators. Therefore, the main goal of this paper is to establish and assess the socio-economic and ekistical spatial differentiation of the border areas of the Central Black Earth Region in the conditions of attractiveness of regional metropolises. To achieve the stated goal it is needed to identify and analyse the impact of regional metropolises on the polarization of socio-economic regional development as well as to determine trends in the development of socio-economic systems of the Central Black Earth Region. The assigned set tasks have been achieved with the use of methods of spatial-temporal, system, and statistical analysis as well as geoformation mapping (ArcGIS) and the results of expeditions in 2018-2020. The study has established that the high attractiveness of regional metropolises predetermined spatial polarization in the socio-economic development of regions and regional settlement systems of the territories bordering Ukraine in the Central Black Earth Region and that both the border areas themselves, except for the Belgorod one, and most territories of the Central Black Earth regions are located in the area of active depopulation and low population density. It is concluded that the laws of urbanization processes development and the coronavirus pandemic will strengthen settlement deconcentration, the growth of classical and structural suburbanization.
\end{abstract}

Keywords-spatial, metropolis, Central Black Earth Region, socio-economic, settlement, ekistics.

\section{INTRODUCTION}

Intraregional contrasts of socio-economic and ekistical (settlement) differences continue to increase and they will continue in the future, despite the regional policy of the equalising vector. In a market economy, business and people prefer territories with competitive advantages. Regional metropolises act as competitive sources: metropolisation transforms the region's space, involves territories in modernization and innovation processes but results in stagnation and/or degradation of remote peripheral areas.

Modern socio-economic and ekistical changes in Russia tend to form in the context of a narrowed 'corridor of opportunities' complex demographic, unstable geo-economic and geopolitical situations which occur with due account for development features and specifics of the border regions. The border situation with Ukraine in the Belgorod, Voronezh, and Kursk regions of the Central Black Earth Region (CBER) impacts on social, demographic, and economic indicators of the border areas and their municipalities, and, to a much lesser extent, on the settlement being one of the most important structures of society. Settlement is an inertial system which is more resistant to social life changes than manufacturing locations [1,2]. Its main feature is self-development. But this statement does not mean that you do not need to know the factors and trends of the real development of socio-economic systems in order to optimize management and innovative development of regions.

The Central Black Earth Region is a small region in terms of population, with a persistent long-term tendency of population decrease typical for many regions of the country as a result of migration outflows and natural population decline observed in 
the recent decades. During the Soviet period, mainly during industrialization, which coincided with urbanization in the region, the urban population increased in all population classes in the cities, in the post-Soviet period, most cities were marked by depopulation, with the exception of regional centers metropolises - centers for meeting the needs of the population economic, social, educational, scientific, and legal ones. The trend of population concentration in large cities, regional centers has become a reflection of the patterns of modern urbanization processes, transformation of the settlement system, which has changed the development model of urban networks.

The Russian-French symposium [3], the works of the wellknown metropolisation researchers $[4,5,6]$, our research $[10$, 17] and articles of a number of leading geographers and social scientists were devoted to the transformation of the urban settlement system [7, 8]. Pinpoint investments and subsequent economic growth [9] will result in the model of centre-periphery territorial division. Urban agglomerations transform into the centre and other territories become the periphery. At the same time, the economies of the agglomeration and the periphery are not exposed to convergence, the centre is developing and the periphery is degrading.

This study examines the concept (model) of emerging inequality between regional metropolises and other cities and territories subject to the metropolis.

Our research was aimed at the territories of the Belgorod, Voronezh and Kursk regions which have common borders with Ukraine.

The main goal of this paper: to establish and assess the socioeconomic and ekistical spatial differentiation of the border areas of the Central Black Earth Region in the conditions of attractiveness of regional metropolises. Objectives: to identify and analyse the impact produced by regional metropolises on the polarization of socio-economic development of the regions, the level of contrast in regional settlement systems; to determine trends in the development of socio-economic systems of the Central Black Earth Region.

System of concepts. A regional metropolis of the region (a metropolis) refers to the main city, the centre of political and economic life with enhanced concentration of the urban population. Metropolisation is the process of metropolis development, the dominance of capital centre in socioeconomic, political and spatial aspects (caused by urbanization development). The metropolitan area is identical to the concept of 'agglomeration'.

Population settlement means the process of distribution and redistribution of the population over the territory and its result a network of settlements.

\section{METHODS}

Materials. The present article observes the classic works of prominent scientists on the problems of settlement, the results of their own research on the settlement systems in Central Russia, the results of expedition surveys of municipalities in 2018-2020, and official statistics from the Federal State Statistics Service (Rosstat). A significant place in the study is given to combining different sources of statistical information and materials of expert interviews with the administration of rural settlements.
Methods: The solution of the main tasks of the research was achieved by using the methods of spatial-temporal analysis, comparative-geographical, statistical, by combining official statistics with sociological methods. A considerable place in the study is given to geoinformation mapping (geoinformation technologies - ArcGIS), which made it possible to visually represent the temporal slice of processes and phenomena, and at the same time to reflect the attractive power of the regional metropolis for the population.

\section{MAIN PART}

\subsection{Metropolisation of regional centres in spatial socio-} economic development of regions

It has become difficult and often impossible to have urban growth due to the transition of most country's regions to the depopulation stage. The exception included the capitals of the Belgorod, Voronezh and Kursk regions in the Central Black Earth Region, which are highly attractive for internal and external migrants. The demographic success of metropolitan areas is the result of the interaction of many factors, but it is our opinion that the dominant one included multifunctional economic structure and metropolitan functions. They made it possible for regional centres to develop successfully, to prevail in the spatial organization of their territory, and to become metropolises. A significant role in the formation of metropolitan areas was played by urbanization processes [10] which changed the territorial distribution of production and primarily the population settlement, including its forms.

In the Belgorod region, an intensive development of the Kursk magnetic anomaly and the development of ferrous metallurgy contributed to the formation of another metropolis - the city of Stary Oskol: together with the city of Gubkin, the polycentric Starooskolsko-Gubkin (bipolar) metropolis was formed. As a result, in the spatial organization of urban settlement in the Central Black Earth region, systems and subsystems of different hierarchical levels have been formed, with different attractor possibilities inviting the population and business, with the Belgorod, Starooskolsko-Gubkinsky, Voronezh, Kursk metropolises playing the leading roles in the local settlement system of the first order.

Rapid development of metropolises in the border areas of the Central Black Earth region at the end of the twentieth century led in the twenty-first century to the gaps in socioeconomic indicators between the metropolises and their surroundings, as it is evidenced by the data in the table (please see the table). 
TABLE I. THE PERCENTAGE (\%) OF METROPOLITAN AREAS IN THE OVERALL SOCIO-ECONOMIC INDICATORS OF THE BELGOROD, VORONEZH AND KURSK REGIONS IN 2018

\begin{tabular}{|c|c|c|c|c|}
\hline & \multicolumn{4}{|c|}{ Metropolises } \\
\hline & $\begin{array}{c}\text { Urban district, } \\
\text { Belgorod }\end{array}$ & $\begin{array}{c}\text { Starooskol } \\
\text { municipality } \\
\text { district }\end{array}$ & $\begin{array}{l}\text { Urban district, } \\
\text { Voronezh }\end{array}$ & $\begin{array}{l}\text { Kursk } \\
\text { municipality } \\
\text { district }\end{array}$ \\
\hline Population size & 25.4 & 16.8 & 45.2 & 40.6 \\
\hline Number of doctors & 49.6 & 15.7 & 74.0 & 62.3 \\
\hline Number of hospital beds & 51.8 & 12.0 & 60.5 & 43.9 \\
\hline Number of people employed & $21.5^{*}$ & 13.7 & $56^{* * *}$ & no data \\
\hline Commissioning of residential buildings & 13.5 & 12.7 & 65.3 & 49.1 \\
\hline Investment in fixed capital & 27.2 & 21.4 & 55.6 & 17.7 \\
\hline Manufacturing & 11.4 & 27.0 & 40.2 & 51.5 \\
\hline $\begin{array}{l}\text { The amount of work performed in the construction } \\
\text { industry }\end{array}$ & 19.7 & 14.4 & no data & 51.5 \\
\hline
\end{tabular}

* for full range of enterprises and organizations; * * excluding small businesses. The table is compiled and calculated according to $[11,12,13,14 \ddot{\mathrm{E}}$

The metropolises regions bordering the Ukraine accommodate half of the total population (in the Belgorod region these are two cities), the major number of doctors (three quarters in Voronezh), hospital beds, which has had a negative effect on medical care in the periphery during the 2020 coronavirus pandemic which has exposed the 'weaknesses' of the health system (not just the periphery) - it is the result of 'optimization' social sphere of the country.

In our opinion, the number of employees in the metropolises which is based on a sociological survey of the population of urban districts (UD) of the Belgorod and Kursk cities in the summer of 2020 is significantly higher than official data: a significant part of those working in the capitals of the regions are residents of suburban areas, commuting migrants, who are not always officially registered by employers.

A significant retail turnover in the metropolises (despite the presence of large retail chains in municipal areas) is evidence of the concentration of consumers, particularly, middle class - shuttle migrants - in its composition. The concentration of trade turnover is especially significant - $62 \%$ - in the metropolis of Voronezh, with its population of over one million.

Housing commissioning is polarized by regional centres: from $26.2 \%$ in Belgorod and Stary Oskol (in total) up to $65.3 \%$ in Voronezh. The 'modest' results of the two metropolises of the Belgorod region can be explained by external reasons: advanced classical suburbanization middle class movement to the suburbs; support provided by the Belgorod mortgage corporation for individual housing construction. Analysis of parcels of land allocated from 2007 to 2017 to the population indicates a further contraction of the population in two metropolitan areas. Of the 34 thousand allocated parcels of land, $69 \%$ were in the city of Belgorod and the Belgorodsky region, $20 \%$ - in the StarooskolskoGubkinsky agglomeration, $11 \%$ - in the rest of the region. It should be noted that buildings are practically stopped to be constructed in some municipal areas of the periphery parts in the Belgorod, Voronezh and Kursk regions. The residents can see no prospects for their children in their native village or district. There is a significant gap in fixed capital investment between Voronezh $(55.6 \%)$ and Kursk (17.7\%). In Voronezh, the investment share is higher than the population share by $10.4 \%$, in Kursk, there is an opposite situation. However, we believe that in the coming years investments will significantly decrease in metropolises but will increase in their suburbs, in private housing construction. The 2020 coronavirus pandemic, a new reality facing the world, will become a factor for increased changes.

Major changes have taken place and will take place in the functional structure of the regional centres and employment: capital city functions are developing, both service sector and information services are growing. The main paths of economic development are related not only to the development of post-industrial functions but also to the maintenance of industrial specialization focused on regional and foreign markets. The share of manufacturing industries in regional centres is highly differentiated - from $38.4 \%$ (Belgorod, Stary Oskol) to $51.5 \%$ (Kursk) but the environmental codes and standards, requirements for urban environment quality are highly likely to result in reduced manufacturing, removal of enterprises outside the metropolitan areas to the suburbs, and eventually development of structural suburbanization.

Regional centres will continue to maintain and increase many of their leading socio-economic positions in the future, which will be facilitated by diversified economic structure, concentration of financial and power levers, better conditions for development and further expansion of small and mediumsized businesses - these are driving forces both for businesses and population.

Metropolises hypertrophy can cause certain risks within its own and subordinate territories: infrastructure collapse, migration vacuum cleaner, and social polarization are actual and very complicated challenges [6] for regional metropolises as such: gentrification, expensive real estate, and growing inequality.

The growth of population, human capital, and settlement transformation is promoted by strong attraction of regional centres and a number of objective advantages offered by a large city.

3.2 Metropolisation in population concentration and settlement

The urbanization processes (we have already discussed them earlier) have resulted in population concentration in large cities and development of urban agglomerations. The Belgorod, Voronezh and Kursk regions have four agglomerations (metropolitan areas) formed with a total area of 44,919 sq. $\mathrm{km}$ and a population of $3.6 \mathrm{mln}$ people (Fig. 1) 
(for agglomeration delimitation method and spatial structure, please see source [11]).

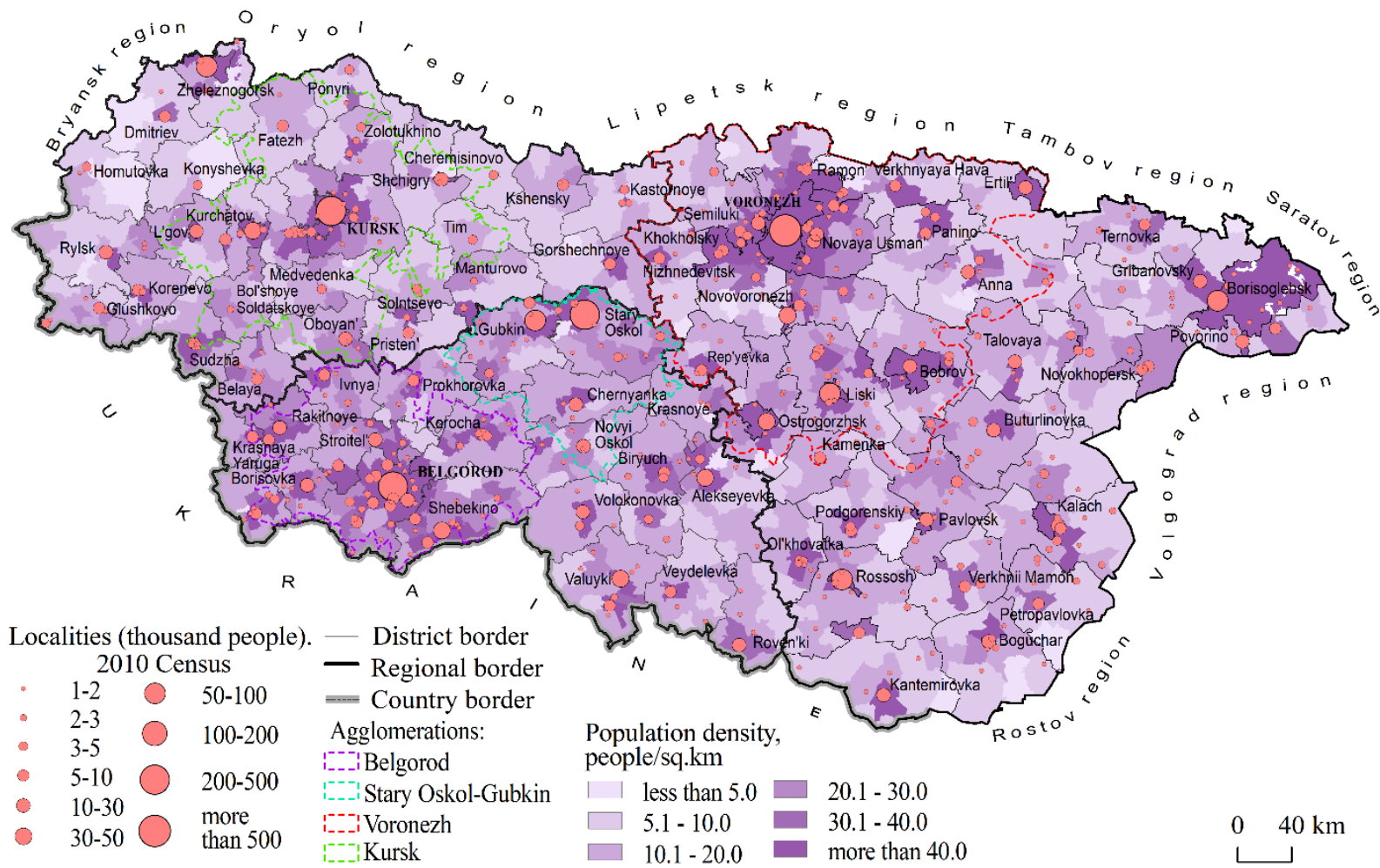

Fig1 Regional settlement systems of the CBER border areas (source [11]) (agglomeration delineation, population density - as of 2017; population density of localities - according to the 2010 census data)

The demographic growth of metropolises, the concentration of administrative and managerial functions, and the socio-economic potential have given the capitals additional opportunities to compete for population (and investment) but also led to 'space compression' [15] territorial polarization of economic, social and demographic development [16], changes in human capital quality, which may negatively affect innovations penetration into nonmetropolitan areas. Consistently high indicators of socioeconomic development are characteristic only for metropolises and, to a lesser extent, for their areas: they have a favorable demographic situation, a developed social sphere, low unemployment, a large volume of investments in fixed assets, high purchasing power and housing security.
Everything stimulates migration of the population in the direction from the village to the city, leading to the instability of rural settlement.

The GIS-constructed cartogram of population changes in the regional settlement systems bordering Ukraine by cities and rural settlements of the Central Black Earth Region confirms the conclusions on significant differentiation of population changes from 2010 to 2018 , concentration of people mainly in regional metropolises and their suburbs (agglomerations) (Fig. 2). 


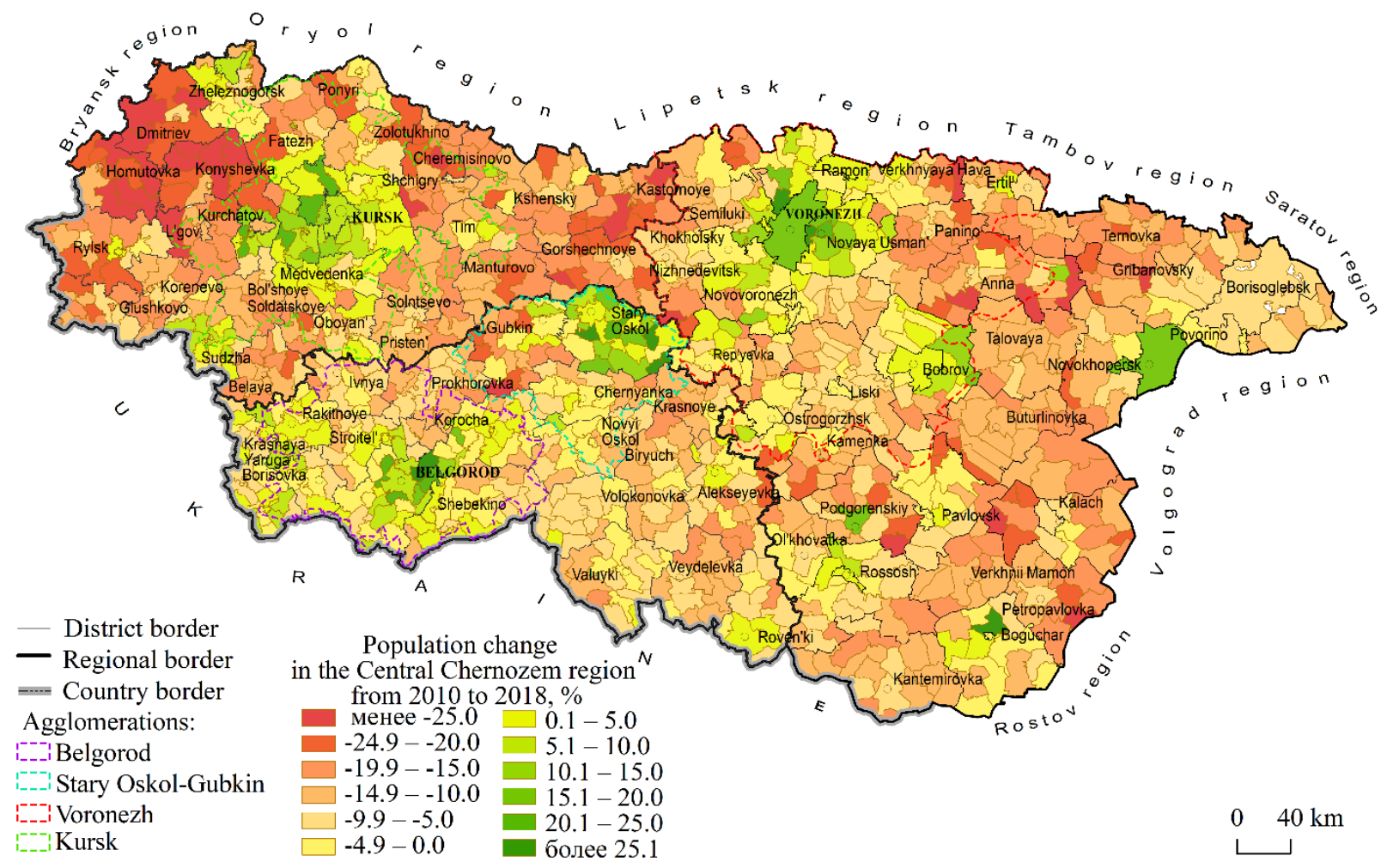

Fig2 Population dynamics. Belgorod, Voronezh and Kursk regions. 2010-2018

It has become impossible to increase the population of most small cities, towns, and rural localities due to the country's transition to depopulation stage, the 'glamorous' image of a large city in the media, and industrial methods of agricultural production which have reduced the number of employees. Population migrations from small towns and rural areas reduce the number of their inhabitants, increase instability of settlement network, and increase the territorial contrast between urban and rural populations. There are areas of stable population reduction formed - settlements which are distant from big cities and population shrinkage areas regional metropolises and, to a lesser extent - exometropoles [17]: Valuyki and Alekseevka in the Belgorod region; Bobrov, Borisoglebsk, and Rossosh in the Voronezh region; Zheleznogorsk and Sudzha in the Kursk region.

The actual CBER municipal areas and urban districts bordering Ukraine have different demographic potential in terms of scope. As for the number of people living in frontier areas the first place is taken by the Belgorod region (by $27 \%$ in 2002 and 2019), the second place is occupied by the Kursk region (13\% and $10 \%$, respectively), in the Voronezh region $-6 \%$ and $5 \%$. The share of the CBER border population is relatively small $-9.5 \%$ in 2002 and $8.8 \%$ in 2019 . We would like to note that in 2002-2019, the number of people living in three regions has decreased by $5.1 \%$ (calculated from [1113]). The population stabilization in the border areas of the Belgorod region is caused by an increase in the suburban area of the metropolis - the Belgorod region (by $38 \%$ ), in one of the nine frontier UD which has radically changed the overall picture of the region and the district.

The main condition for the viability of any locality (and population) is its position in the 'centre-periphery' gradient [9], the functional structure, economy diversification or its absence, and labor market possibilities. Against the background of metropolises, the potentials of municipal areas and peripheral urban districts are limited by all indicators and encourage population to renewed leaving for seasonal work [18], shuttle migration or movement to a large city. As a result, there is development stagnation and depopulation which make it really difficult to maintain spatial distribution process for new achievements - diffusion of innovations.

\section{CONCLUSION}

The development of metropolises and metropolitan areas is a natural result of the interaction of many factors; urbanization processes dominated, which coincided in the Central Black Earth Region with the industrialization of regions. The functions of the capital and the multifunctional structure of the economy played a certain role in the "elevation" of the metropolises over the territory under their control. The models for the development of cities in the border areas of the Central Black Earth Region in the 21st century are different: at one pole of regional settlement systems there are metropolises in the rank of large and major cities, on the other there are medium-sized cities with apparent depopulation, and between them there is a thin layer of large and medium-sized cities with unstable development.

The formation of regional metropolises was accompanied by a radical transformation of the rural settlement system, the decrease in the rural population, and by the shrinking of the population of settlements.

The factors of the rural settlement transformation were the impact of globalization processes on the countryside, industrial methods of production in agriculture, sub-standard environment, the pull of big cities for rural residents, and a number of other reasons. 
The high attractiveness of regional metropolises has changed the spatial socio-economic, demographic development, and the settlement system of the regions bordering Ukraine in the Central Black Earth Region: Belgorod, Voronezh and Kursk regions. There is one polycentric and two monocentric polarized spatial settlement structures in place which draw population, business, and social infrastructure into metropolises.

The border areas themselves, except for Belgorod one which is part of the Belgorod agglomeration, are located in the area of active depopulation and low population density, just as most territories of the CBER regions.

Belgorod region has always been and still remains the leader in terms of the number of people living in the border territories due to the economic and geographical position, the next place is occupied by Kursk and Voronezh regions.

The contactness of the border position, low barrier functions of the border between Russia and the Ukraine, the attractive force of the metropolitan city of Kharkov and its suburbs were great until 2014. Currently, barrier functions have grown, contact functions have decreased.

Regional metropolises and their agglomerations will keep influencing the spatial social organization. The coronavirus pandemic will increase settlement deconcentration, cause increased classical and structural suburbanization and growth of remote employment in the suburbs. Outside metropolitan areas, there may be innovation-related difficulties you should take into account in the long-term placement of modern production facilities.

Management system optimization can be facilitated through identification, examination, and forecast of regional level socio-economic and ekistical processes.

\section{ACKNOWLEDGMENT}

The publication has been prepared as part of the RFBRsupported research project No 20-05-00074.

\section{REFERENCES}

[1] S.A. Kovalev, N.Ya. Kovalskaya. Geography of the USSR population, Moscow, 1980, $287 \mathrm{p}$.

[2] A.A. Tkachenko. "Key concepts of settlement theory: an attempt to rethink”, Moscow, Series 5, Geography, vol. 2, 2018, pp. 10-15.

[3] O.I. Vendina, M.V. Zotova, V.A. Kolosov. "International seminar: Metropolisation and Urban Networks. Proceedings of the Russian Academy of Sciences", Geographical series, vol. 2, 2010, pp. 130-131.

[4] N.V. Zubarevich. "Globalisation impact on the development of Russian regions: results and prospects. Large cities and globalisation challenges”, Edited by V. A. Kolosov and D. Eckert. Smolensk, 2003, pp. 37-53.

[5] V.A. Kolosov, O.I. Vendina, D. "Eckert. Regional centres in the context of globalisation: comparative research problems. Large cities and globalisation challenges", Smolensk, 2003, pp. 5-15.

[6] R. Florida, New urban crisis: gentrification, expensive real estate, growing inequality, and what we should do about it, Moscow, IG Tochka. Translators: N. Dovgulevich, V. Karpyuk, Yu. Levchuk et al, 2018, 368 p.

[7] N.V. Gontar, "Metropolisation as a territorial phenomenon and a factor of territorial capitalization", Regional economy: theory and practice, vol. 10 (385), 2015, pp. 27-35.

[8] A.G. Druzhinin, "Metropolisation as a dominant trend of territorial social organisation in the post-Soviet period: universal manifestations and South-Russian specifics", Geographical Bulletin, vol. 3(11), 2009, pp. 54-61.

[9] J. Friedmann, Regional Development Policy: A Case Study of Venezuela. MIT Press, 1966, 27 p.

[10] N. Chugunova, T. Polyakova, S. Ignatenko, Z. Buryak. "Polarization of the Regional Settlement System as a Reflection of Neoliberal Urbanization Processes", 19th International Multidisciplinary Scientific GeoConference SGEM 2019. Conference Proceedings. Vol. 19. Ecology, Economics, Education and Legislation. Issue 5.2. Ecology and Environmental Protection, Albena, Bulgaria, 2019, pp. 603-610. DOI: https://doi.org/10.5593/sgem2019/5.22.

[11] Main indicators of socio-economic situation of municipal areas and urban districts of the Belgorod region (2015-2019). Statistical book, Belgorod, Belgorodstat, 2020, 292 p.

[12] Economic and social development indicators for urban districts and municipal areas of the Voronezh region, Voronezh, 2019, $180 \mathrm{p}$.

[13] Statistical Yearbook of the Kursk Region. 2019. Statistical book. Kursk, Kurskstat, 2019, 444 p.

[14] Socio-economic atlas of cities and districts of the Kursk region. Kursk, Kurskstat, 2018, 33 p.

[15] P. Hagget. Geography: Synthesis of Current Knowledge. Moscow, Progress, 1979, $421 \mathrm{p}$.

[16] N. V. Chugunova, N.V. Likhnevskaya. "Spatial Differentiation of the Standard of Living in the Population as a Representation of Disproportions in Socioeconomic Development", A Case Study of Belgorod Oblast, Journal. Regional Research of Russia, 9(3), 2019, pp. 267-277.

[17] N.V. Chugunova, A. G. Narozhnaya. "Internal structure of agglomerations and urban space of the Central Black Earth Region by means of GIS. City Management", Theory and practice, 2020,vol. 3 (37), pp. 56-62

[18] T. Nefedova, A. Nikulin. Rural Russia: spatial compression and social polarization. http://demoscope.ru/weekly/2010/0437/analit02.php (accessed $01.10 .2020)$
URL: (accessed 